destroy all the ammonium chloride and to finally test for nickel in a volume of some i $5 \mathrm{cc}$. under ideal conditions.

The ether separation, as based on the solubility of ferric chloride in ether under the above conditions is, in all probability, not restricted to the determination of nickel or aluminum, but may possibly be applied in the separation of small amounts of zinc from iron. The separation of uranium and iron by ammonium carbonate and sulphide is far from satisfactory if the uranium be small in amount. Possibly in this case as well, the ether treatment may result in a decided improvement.

LABORATOR: OF RICKETTS AND BANKS. NEW YORK.

[CONTRIBUTIONS FROM THE HAVEMEYFR LABORATORIES, COLUMBIA [NIVERSITY, No. I6.]

\title{
LABORATORY METHOD FOR THE CONTINUOUS AND UNIFORM GENERATION OF ACETYLENE, AND FOR ITS PURIFICATION.
}

BY J. A. Mathetws.

Received january 2, 2900 .

$\mathrm{C}^{\mathrm{OR}}$ most purposes in which it is desired to employ a stream $\Gamma$ of acetylene, no purification is necessary, provided the gas has been properly generated from the usual quality of commercial carbide now being produced. Analyses from various sources show that the impurities in acetylene from this source rarely amount to I per cent. and a good part of this is likely to be nitrogen. The combined amounts of hydrogen sulphide, hydrogen phosphide, and ammonia seldom exceed 0.2 per cent. In order that the amount of impurities may be as small as possible it is necessary that the gas be produced in the cold. This cannot be done when water is allowed to drip slowly upon the carbide, and furthermore this method causes the gas to be given off spasmodically and the lime residue often bubbles or froths to such an extent that solid matter in considerable amounts may be carried over with the gas. In obviating all these difficulties the following method has proved successful.

The fragments of calcium carbide are placed in a wide-mouthed bottle. They may, with advantage, be suspended in a basket of coarse wire netting, which will keep the carbide away from the 
lime residue, and also allow it to be withdrawn at any time. The carbide is covered with an abundance of absolute or 95 per cent. alcohol, and the bottle closed with a two-hole stopper. Through one hole water can be led from a reservoir bottle, and in the other an outflow tube is fitted. If 95 per cent. alcohol is used, the water therein serves to start the generation of acetylene and to expel the air from the apparatus. If, now, water be added drop by drop it comes slowly into contact with the carbide and a steady production of acetylene results. Unless the amount of alcohol present is very small and the rate of generation very rapid, no material rise in temperature ensues. After the addition of water has been stopped, the evolution of gas may be allowed to proceed until the bubbling ceases; the alcohol may then be decanted from the residue and distilled, and, rejecting the first few cubic centimeters, the rest of the distillate will be nearly absolute alcohol.

If it is desired to purify the acetylene, any one or more of several methods may be employed. No single purifying agent which has as yet been advocated, meets all the requirements. For general convenience and thoroughness the following combination of methods is suggested :

The acetylene generated as described above is passed into a solution of 15.6 parts of crystallized copper sulphate in 100 parts of water, to which is added 5 parts of dilute sulphuric acid, ${ }^{1}$ I volume of sulphuric acid to 4 volumes of water. This solution, besides retaining any vapor of alcohol and also the ammonia and hydrogen sulphide, is especially useful for absorbing hydrogen phosphide. As an additional safeguard the acetylene is next passed through one or two towers filled with coarse bits of pumice stone which have been saturated with an acetic or sulphuric acid solution of chromic acid; ${ }^{2}$ or, in place of a second tower, a strong sulphuric acid solution of chromic acid may be used. By this means any of the three chief impurities, which might escape absorption in the copper sulphate solution, will be completely oxidized. A small amount of these purifying materials will serve for a large volume of gas, and the acetylene should issue both dry and pure and possessing a faint and agreeable odor.

1 Hempel and Kahl : Ztschr, angere. Chem., 53, I898.

2 Ullmavn: J. für. Gasbeleucht, 42, 198, 374 (1899). 
A return of the strong, irritating odor indicates that the purifiers have become exhausted.

The purification of acetylene by means of moist chloride of lime or sodium hypochlorite, as suggested by Odernheimer' and Lunge ${ }^{2}$ or as modified by Wolff', is impracticable because of the instability of the solutions and because chlorine and chlorination products of acetylene are produced, which must then be removed by lime. Frank's method, "using strongly acid solutions of copper or iron chloride, does not seem very efficient, nor is the employment of bromine as a purifier convenient for laboratory use. The combination of Hempel's and Ullmann's methods seems to meet all the requirements and is easily and conveniently arranged.

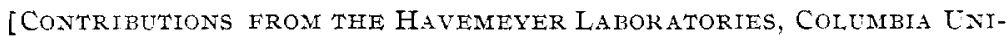
versity, No. I T.]

\section{THE CARBIDE OF GOLD.}

BF J, A. MAThews and L, I. WATters.

Received Janutry 2,1000 .

$E$ XPLOSIVE compounds restulting from the action of acetylene and mercuric salts have been known for many years. These compounds are for the most part flocculent precipitates which retain water with more or less tenacity, and at temperatures which will render them anhydrous they are apt to explode violently. The earlier investigators of these acetylides did not recognize them as true carbides and their analyses show the presence of hydrogen and oxygen, which are reported as constituent atoms of the molecule. Berthelot," who did a great deal of work upon acetylene derivatives, speaks of copper acetylide as "cuproacetyloxide," and gives it the formula $\left(\mathrm{C}_{2} \mathrm{Cu}_{2} \mathrm{H}\right)_{2} \mathrm{O}$. Rebou1 ${ }^{6}$ gives silver acetylide as $\left(\mathrm{C}_{2} \mathrm{HAg}\right)_{2}+\mathrm{Ag}_{2} \mathrm{O}$ and Blochmann ${ }^{7}$ gives respectively, $\mathrm{C}_{2} \mathrm{H}_{2} \mathrm{Cu}_{2} \mathrm{O}$ and $\mathrm{C}_{2} \mathrm{H}_{2} \mathrm{Ag}_{2} \mathrm{O}$. All of these might better

1 Chem, Ztg, 22, 21 .

2 Ztschr. angew. Chem, 65 I (1897).

3 Chem. Ztg., 22, 28I; Wolff treats the gas first to remove ammonia and then with hypochlorite, thus elimitrating the danger of forming nitrogen chloride, which he says is possible.

* Zischrangere. Chem., ro50 (1898).

5 Arn. chim. phys. [4], 9. 425 .

6 Compt. rend., 54 , I2:29.

7 Ann. Chem. (Liebig), $573,176,177$. 